\title{
Improved myocardial lactate extraction after propranolol in coronary artery disease: effected by peripheral glutamate and free fatty acid metabolism
}

\author{
TORSTEN TOFTEGAARD NIELSEN, JENS PEDER BAGGER, \\ ANNE THOMASSEN
}

From the Department of Cardiology, Aarhus Kommunehospital, and the Departments of Internal Medicine III and Clinical Chemistry, Aarhus Amtssygehus, Aarhus, Denmark

SUMMARY Ten patients with chronic effort angina and coronary artery disease (luminal diameter reduction $>75 \%$ ) were stressed by atrial pacing ( 140 beats/minutes) before and 15 minutes after intravenous propranolol (mean dose $7.4 \mathrm{mg}$ ). Myocardial substrate exchange of oxygen, blood lactate, plasma free fatty acids, citrate, glucose, glutamate, and alanine as well as coronary sinus blood flow were measured. Coronary sinus blood flow, oxygen consumption, and systemic haemodynamics did not change after propranolol. Propranolol did not influence arterial lactate concentration, and it reduced the arterial concentration of free fatty acid by $37 \%$ and increased that of glutamate by $21 \%$. During pacing myocardial lactate extraction increased in all 10 patients; in two lactate release was converted to lactate uptake. Propranolol reduced free fatty acid uptake and increased glutamate uptake during pacing. For both substances the changes in aortocoronary sinus differences or in uptake or both correlated positively with the changes in their delivery to the heart from extracardial sources (arterial concentrations/loads). In the unstressed state before pacing, aortocoronary sinus lactate differences correlated inversely with free fatty acid differences and positively with those of glutamate. During pacing the relation between lactate and glutamate differences remained positive while the inverse correlation between lactate and free fatty acid differences was lost. Myocardial citrate release was halved during pacing and recovery. Propranolol did not influence alanine or glucose exchanges.

An improved myocardial lactate extraction after propranolol administration may be secondary to decreased free fatty acid uptake or increased glutamate uptake or both. In the unstressed state both mechanisms may be of importance. During pacing induced ischaemia, increased glutamate uptake is more likely than reduced free fatty acid uptake to be the mechanism responsible for the improvement in myocardial lactate extraction. The propranolol mediated alterations in myocardial substrate exchanges may reflect the extracardial effects of the drug.

The well established antianginal effect of beta adrenoceptor blocking drugs is attributed to decreased oxyen requirements secondary mainly to a reduced heart rate. ${ }^{12}$ In addition there is evidence in patients with coronary artery disease of a metabolic effect that improves myocardial carbohydrate

Requests for reprints to Dr Torsten Toftegaard Nielsen, Department of Cardiology, Aarhus Kommunehospital, DK-8000 Aarhus C, Denmark.

Accepted for publication 12 September 1985 utilisation, independently of the haemodynamic actions of such agents. ${ }^{3}$ Increased myocardial lactate extraction has been reported after administration of beta adrenergic antagonists. ${ }^{3-5}$ The antilipolytic effect of beta blockers ${ }^{6}$ with subsequent reduction in circulating free fatty acid concentration and hence a reduction in substrate competition, has been proposed as the mechanism responsible for the improved lactate extraction. ${ }^{4}$ In the normal heart in which the capacity of free fatty acid oxidation is high and unrestricted this 
mechanism seems of regulatory importance. ${ }^{78}$ In the ischaemic heart the capacity for free fatty acid oxidation is limited. ${ }^{9}$ Therefore a reduction in free fatty acid supply after beta blockade cannot be expected to improve carbohydrate utilisation to the same degree as it does in the normal heart. Myocardial carbohydrate breakdown can proceed only to the extent that oxidation of the glycolytically produced reduced nicotinamide adenine dinucleotide takes place. ${ }^{10}$ This occurs indirectly via the malate-aspartate shuttle, ${ }^{11}$ and this is in turn dependent on the import of glutamate into the myocardial cell. ${ }^{12}$ We have reported positive relations between glutamate uptake and both glucose and lactate uptake in coronary artery disease in the unstressed state. ${ }^{13}$

To elucidate further the mechanisms underlying alterations in myocardial metabolism after beta blockade we have examined myocardial substrate exchanges of lactate, free fatty acids, citrate, glucose, glutamate, and alanine during atrial pacing in patients with coronary artery disease before and after the administration of propranolol.

\section{Patients and methods}

Ten men (mean age 53, range 40-66 years) were studied after their informed consent had been obtained. All had chronic effort angina with ST segment depression ( 2 to $5 \mathrm{~mm}$ ) during exercise stress testing. Three patients had had myocardial infarction more than six months before. None had additional heart disease, hypertension, or metabolic disorders. The patients had undergone left ventriculography and coronary angiography a week before the study. Seven patients had important stenoses (a reduction in luminal diameter of $>75 \%$ that was resistant to glyceryl trinitrate) of three vessels, of two vessels in two patients, and of one vessel in one patient. All except one had stenosis of the anterior descending branch of the left coronary artery. Mean (SD) left ventricular end diastolic pressure was 11 (2) $\mathrm{mm} \mathrm{Hg}$ and the ejection fraction was $64(6) \%$. Antianginal medication except for glyceryl trinitrate (verapamil in five patients, propranolol in three, metoprolol in one, and combined nifedipine and metoprolol in one) was stopped a week before the study; glyceryl trinitrate was allowed up to four hours before the examination.

\section{PROCEDURE}

The patients were examined in the supine position without sedation in the morning after an overnight fast. A Wilton Webster thermodilution pacing catheter was advanced to a midposition in the coronary sinus via an antecubital vein. Coronary sinus blood flow was measured by continuous infusion of saline solution $(36 \mathrm{ml} / \mathrm{min})$ for $20-25$ seconds for each measurement. ${ }^{14} \mathrm{~A}$ Teflon catheter for arterial blood sampling and pressure measurements was inserted into the distal aorta percutaneously via a femoral artery. The catheters were kept patent by intermittent infusion of saline solution containing heparin (total dose below $\mathbf{3 0 0}$ units).

Coronary sinus pacing was carried out at a constant rate of about 140 beats/minute until intolerable angina occurred of for at least 10 minutes. Propranolol $(0.1 \mathrm{mg} / \mathrm{kg}$ ) (mean (SD) dose $7.4(0.7) \mathrm{mg}$ ) was given intravenously 30 minutes after the end of pacing for two mintues. Fifteen minutes later the patients were stressed by repeated coronary sinus pacing of same duration and rate as during the first pacing period. During the two pacing periods the coronary sinus electrode was maintained in the same position by fluoroscopic control.

During both pacing studies coronary sinus blood flow, heart rate, and blood pressure (Elema Schönander transducer) were determined in triplicate in resting state, twice during pacing after onset of slight angina (in three patients only one measurement was made because severe angina developed), and at three and five minutes into recovery. In each patient haemodynamic measurements and blood sampling were obtained at the same times during the two studies. After separation of samples for the measurement of oxygen saturation, blood samples were collected into heparinised ice cooled glass tubes. Blood was deproteinisated for blood lactate determination and centrifuged for plasma analysis at $4^{\circ} \mathrm{C}$. After storage at $-80^{\circ} \mathrm{C}$ for a few days, samples were analysed for concentrations of blood lactate, plasma free fatty acids, plasma glucose, plasma citrate (10 patients), and plasma glutamate and plasma alanine (seven patients) as described elsewhere. ${ }^{1516}$

\section{STATISTICAL ANALYSIS}

Fractional myocardial substrate extraction was calculated as the aortocoronary sinus difference divided by the arterial concentration multiplied by $100(\%)$. Net substrate exchange across the heart was calculated from the aortocoronary sinus difference, coronary sinus blood flow, and haematocrit. Data are given as mean (1 SD) or mean and range. The paired two tailed $t$ test and linear regression analysis were used for statistical evaluation. A probability value of $<0.05$ was considered to be significant. 

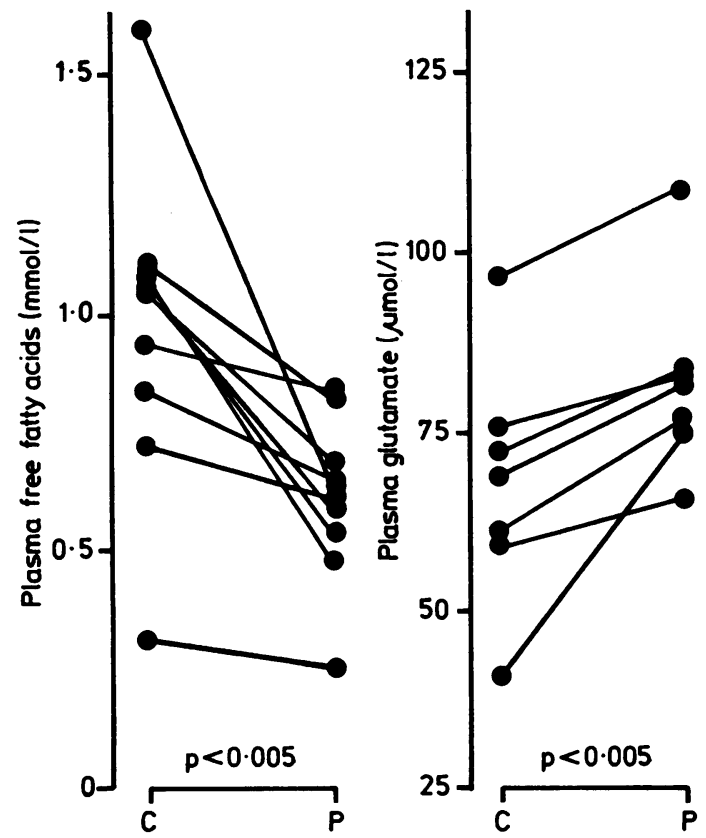

Fig. 1 Arterial concentrations of plasma free fatty acids and plasma glutamate in control state $(C)$ and after propranolol administration $(P)$ in patients with coronary artery disease. Values are means of seven blood samples obtained throughout each study period.

\section{Results}

In the unstressed state before pacing none of the patients had chest pain. All except for one patient with two vessel disease complained of typical angina pectoris during the first pacing period. The mean pacing time of both periods was 305 seconds (range 60-600 seconds). During repeated pacing after propranolol three patients did not develop chest pain, pacing time to onset of angina was increased by 10-120 seconds (mean 80 seconds) in four patients, and remained unchanged in three patients.

\section{HAEMODYNAMIC RESULTS}

Propranolol administration did not change heart rate, systolic aortic pressure, the rate pressure product, or coronary sinus blood flow. Mean (SD) values before and after propranolol were for heart rate at rest $68(17)$ vs $69(11)$ beats/minute and during pacing $139(5)$ vs $140(5)$ beats/minute. Systolic aortic pressure at rest was 140 (5) vs $136(22)$ $\mathrm{mm} \mathrm{Hg}$ and during pacing $130(23)$ vs $125(25)$ mm Hg. Rate pressure product (heart rate multiplied by systolic aortic pressure) at rest was 95 (36) vs 94 (21) beats/minute $\times \mathrm{mm} \mathrm{Hg} \times 10^{-2}$ and during pacing 182 (37) vs 178 (39) beats/minute $\times \mathrm{mm} \mathrm{Hg} \times 10^{-2}$. Coronary sinus blood flow at rest was $119(37)$ to $120(43) \mathrm{ml} /$ minute and during pacing 200 (73) vs $182(62) \mathrm{ml} /$ minute (eight patients only).

After propranolol the aortocoronary sinus oxygen difference increased slightly during pacing, from $119(9)$ to $126(10) \mathrm{ml} / 1 \quad(\mathrm{p}<0.05)$, but was unchanged at rest $(121(21)$ vs 123 (13) $\mathrm{ml} / \mathrm{l})$. Myocardial oxygen consumption (eight patients) did not change; values before and after propranolol were $15.1(6.9)$ vs $14.9(5.5) \mathrm{ml} /$ minute at rest and $24 \cdot 1(10 \cdot 1)$ vs $23 \cdot 0(8 \cdot 1) \mathrm{ml} /$ minute during pacing.

\section{METABOLIC RESULTS \\ Arterial concentrations}

There was no tendency for arterial concentration of metabolites to increase or decrease during each of the two study periods of about 15 minutes. After propranolol the arterial concentrations (mean of concentrations at rest and during pacing and recovery) of plasma free fatty acids decreased by $37 \%$ (from $0.98(0.33)$ to $0.62(0.17) \mathrm{mmol} / \mathrm{l}$ ), increased by $21 \%$ for plasma glutamate (from $68(17)$ to $82(14) \mu \mathrm{mol} / \mathrm{l}$ ) (Fig.1), and decreased slightly for plasma alanine (from 222 (77) to 204 (61) $\mu \mathrm{mol} / \mathrm{l})(\mathrm{p}<0.05)$. No change was found for the other metabolites. Mean arterial concentrations before and after propranolol were-blood lactate $0.78(0.19)$ vs $0.77(0.14) \mathrm{mmol} / \mathrm{l}$, plasma glucose $5.59(0.54)$ vs $5.63(0.51) \mathrm{mmol} / \mathrm{l}$, and plasma citrate 79 (30) vs 82 (25) $\mu \mathrm{mol} / 1$.

\section{Substrate exchange (Table)}

In the resting state propranolol did not influence substrate exchange except that there was an increased aortocoronary sinus difference in glutamate concentrations.

In the control tests atrial pacing induced a release of lactate across the heart in seven patients, while lactate extraction remained positive in three patients including the one who did not complain of angina. After propranolol myocardial lactate extraction increased in all the patients; a mean lactate release of $16 \mu \mathrm{mol} /$ minute was converted to a mean uptake of $13 \mu \mathrm{mol} /$ minute. Propranolol reduced free fatty acid uptake during pacing and at 5 minutes of recovery, both when this result was calculated as aortocoronary sinus difference and as net uptake. Fractional free fatty acid extraction was reduced at 5 minutes of recovery only. Myocardial citrate release was halved during pacing and recovery, both in terms of aortocoronary sinus difference and net release. Aortocoronary sinus glutamate differences always increased after propranolol administration, but the net uptake increased only during pacing. Notably, fractional glutamate extraction remained virtually unchanged. Propranolol did not influence 
Table Myocardial exchange of substrates before and after propranolol administration to patients undergoing atrial pacing

\begin{tabular}{|c|c|c|c|c|c|}
\hline & \multirow[t]{2}{*}{ Rest } & \multirow[t]{2}{*}{ Pacing } & \multicolumn{3}{|l|}{ Recovery } \\
\hline & & & $3 \min$ & $5 \min$ & \\
\hline $\begin{array}{l}\text { Aortocoronary sinus lactate difference }(\mathrm{mmol} / \mathrm{l})(\mathrm{n}=10) \text { : } \\
\text { Control } \\
\text { Propranolol }\end{array}$ & $\begin{array}{l}0 \cdot 15(0 \cdot 09) \\
0 \cdot 19(0 \cdot 10) \\
\text { NS }\end{array}$ & $\begin{array}{l}-0 \cdot 11(0 \cdot 19) \\
0.04(0 \cdot 17) \\
p<0.005\end{array}$ & $\begin{array}{l}0.06(0 \cdot 17) \\
0.20(0 \cdot 10) \\
p<0.05\end{array}$ & $\begin{array}{l}0.14(0.12) \\
0.22(0.09) \\
p<0.02\end{array}$ & \\
\hline $\begin{array}{l}\text { Myocardial lactate extraction }(\%)(n=10) \\
\text { Control } \\
\text { Propranolol }\end{array}$ & $\begin{array}{l}20 \cdot 9(14 \cdot 7) \\
27 \cdot 4(14 \cdot 5) \\
\text { NS }\end{array}$ & $\begin{array}{l}-15 \cdot 6(27 \cdot 2) \\
4 \cdot 4(22 \cdot 0) \\
p<0.005\end{array}$ & $\begin{array}{l}9.9(21.0) \\
26.0(13.9) \\
p<0.05\end{array}$ & $\begin{array}{l}19 \cdot 2(15 \cdot 2) \\
29 \cdot 3(13 \cdot 3) \\
\mathrm{p}<0.01\end{array}$ & \\
\hline $\begin{array}{l}\text { Myocardial lactate uptake }(\mu \mathrm{mol} / \mathrm{min})(\mathrm{n}=8) \text { : } \\
\text { Control } \\
\text { Propranolol }\end{array}$ & $\begin{array}{l}18 \cdot 1(11 \cdot 0) \\
21 \cdot 1(11 \cdot 3) \\
\text { NS }\end{array}$ & $\begin{array}{l}-15 \cdot 9(28 \cdot 8) \\
12 \cdot 8(25 \cdot 5) \\
\mathrm{p}<0.02\end{array}$ & $\begin{array}{l}11 \cdot 1(28 \cdot 7) \\
23 \cdot 1(14 \cdot 1) \\
\text { NS }\end{array}$ & $\begin{array}{l}19 \cdot 3(20 \cdot 8) \\
27 \cdot 3(12 \cdot 3) \\
\text { NS }\end{array}$ & - \\
\hline $\begin{array}{l}\text { Aortocoronary sinus FFA difference }(\mathrm{mmol} / \mathrm{l})(\mathrm{n}=10) \text { : } \\
\text { Control } \\
\text { Propranolol }\end{array}$ & $\begin{array}{l}0.15(0.13) \\
0 \cdot 11(0 \cdot 09) \\
\text { NS }\end{array}$ & $\begin{array}{l}0 \cdot 16(0 \cdot 16) \\
0.05(0 \cdot 10) \\
p<0.02\end{array}$ & $\begin{array}{l}0.13(0.09) \\
0.09(0 \cdot 10) \\
\text { NS }\end{array}$ & $\begin{array}{l}0.15(0.11) \\
0.01(0.09) \\
p<0.02\end{array}$ & \\
\hline $\begin{array}{l}\text { Myocardial FFA extraction }(\%)(n=10) \text { : } \\
\text { Control } \\
\text { Propranolol }\end{array}$ & $\begin{array}{l}19 \cdot 4(7 \cdot 5) \\
22 \cdot 3(15 \cdot 2) \\
\text { NS }\end{array}$ & $\begin{array}{l}15 \cdot 1(11 \cdot 9) \\
6 \cdot 8(18 \cdot 0) \\
\text { NS }\end{array}$ & $\begin{array}{l}15 \cdot 0(12 \cdot 2) \\
13 \cdot 4(16 \cdot 6) \\
\text { NS }\end{array}$ & $\begin{array}{l}16 \cdot 2(12 \cdot 0) \\
0.5(18 \cdot 2) \\
p<0.05\end{array}$ & \\
\hline $\begin{array}{l}\text { Myocardial FFA uptake }(\mu \mathrm{mol} / \mathrm{min})(\mathrm{n}=8) \text { : } \\
\text { Control } \\
\text { Propranolol }\end{array}$ & $\begin{array}{l}12 \cdot 2(6 \cdot 9) \\
8 \cdot 3(6 \cdot 5) \\
\text { NS }\end{array}$ & $\begin{array}{l}21 \cdot 1(24 \cdot 2) \\
7 \cdot 2(14 \cdot 2) \\
p<0.05\end{array}$ & $\begin{array}{l}9 \cdot 6(8 \cdot 7) \\
5 \cdot 3(7 \cdot 7) \\
\text { NS }\end{array}$ & $\begin{array}{l}11 \cdot 7(9 \cdot 6) \\
0 \cdot 7(6 \cdot 1) \\
p<0.02\end{array}$ & \\
\hline $\begin{array}{l}\text { Aortocoronary sinus citrate difference }(\mu \mathrm{mol} / \mathrm{l})(\mathrm{n}=10) \text { : } \\
\text { Control } \\
\text { Propranolol }\end{array}$ & $\begin{array}{l}-5(2) \\
-4(2) \\
\text { NS }\end{array}$ & $\begin{array}{l}-5(3) \\
-2(2) \\
p<0.01\end{array}$ & $\begin{array}{l}-8(3) \\
-4(5) \\
\mathrm{p}<0.05\end{array}$ & $\begin{array}{l}-8(4) \\
-4(7) \\
p<0.05\end{array}$ & \\
\hline $\begin{array}{l}\text { Myocardial citrate release }(\mu \mathrm{mol} / \mathrm{min})(\mathrm{n}=8) \text { : } \\
\text { Control } \\
\text { Propranolol }\end{array}$ & $\begin{array}{l}0.35(0.21) \\
0 \cdot 28(0 \cdot 17) \\
\text { NS }\end{array}$ & $\begin{array}{l}0.61(0.36) \\
0.22(0.26) \\
p<0.05\end{array}$ & $\begin{array}{l}0.59(0.22) \\
0 \cdot 16(0.40) \\
p<0.02\end{array}$ & $\begin{array}{l}0.56(0.36) \\
0.25(0.20) \\
p<0.05\end{array}$ & \\
\hline $\begin{array}{l}\text { Aortocoronary sinus glutamate difference }(\mu \mathrm{mol} / \mathrm{l})(\mathrm{n}=7) \text { : } \\
\text { Control } \\
\text { Propranolol }\end{array}$ & $\begin{array}{l}34(7) \\
43(7) \\
p<0.01\end{array}$ & $\begin{array}{l}19(4) \\
32(8) \\
p<0.01\end{array}$ & $\begin{array}{l}28(5) \\
39(6) \\
p<0.005\end{array}$ & $\begin{array}{l}30(8) \\
41(9) \\
\mathrm{p}<0.02\end{array}$ & \\
\hline $\begin{array}{l}\text { Myocardial glutamate extraction }(\%)(n=7) \text { : } \\
\text { Control } \\
\text { Propranolol }\end{array}$ & $\begin{array}{l}49 \cdot 9(7 \cdot 8) \\
52 \cdot 0(10 \cdot 6) \\
\text { NS }\end{array}$ & $\begin{array}{l}28 \cdot 9(8 \cdot 1) \\
38 \cdot 7(11 \cdot 4) \\
\text { NS }\end{array}$ & $\begin{array}{l}45 \cdot 0(12 \cdot 8) \\
49 \cdot 4(10 \cdot 2) \\
\text { NS }\end{array}$ & $\begin{array}{l}46 \cdot 5(16 \cdot 1) \\
51 \cdot 0(12 \cdot 4) \\
\text { NS }\end{array}$ & \\
\hline $\begin{array}{l}\text { Myocardial glutamate uptake }(\mu \mathrm{mol} / \mathrm{min})(\mathrm{n}=7) \text { : } \\
\text { Control } \\
\text { Propranolol }\end{array}$ & $\begin{array}{l}2 \cdot 39(0 \cdot 87) \\
3.00(1 \cdot 22) \\
\text { NS }\end{array}$ & $\begin{array}{l}2.28(0.94) \\
3.21(0.58) \\
p<0.005\end{array}$ & $\begin{array}{l}2 \cdot 31(1 \cdot 13) \\
2 \cdot 63(1.08) \\
\text { NS }\end{array}$ & $\begin{array}{l}2 \cdot 37(1 \cdot 23) \\
2 \cdot 61(1 \cdot 18) \\
\text { NS }\end{array}$ & \\
\hline $\begin{array}{l}\text { Aortocoronary sinus alanine difference }(\mu \mathrm{mol} / \mathrm{l})(\mathrm{n}=7) \text { : } \\
\text { Control } \\
\text { Propranolol }\end{array}$ & $\begin{array}{l}-20(9) \\
-20(7) \\
\text { NS }\end{array}$ & $\begin{array}{l}-17(8) \\
-15(9) \\
\text { NS }\end{array}$ & $\begin{array}{l}-21(9) \\
-22(10) \\
\text { NS }\end{array}$ & $\begin{array}{l}-21(10) \\
-19(8) \\
\text { NS }\end{array}$ & \\
\hline $\begin{array}{l}\text { Myocardial alanine release }(\mu \mathrm{mol} / \mathrm{min})(\mathrm{n}=7) \text { : } \\
\text { Control } \\
\text { Propranolol }\end{array}$ & $\begin{array}{l}1.41(0.66) \\
1.41(0.76) \\
\text { NS }\end{array}$ & $\begin{array}{l}1.91(0.95) \\
1.58(1.03) \\
\text { NS }\end{array}$ & $\begin{array}{l}1.70(1.01) \\
1.55(1.08) \\
\text { NS }\end{array}$ & $\begin{array}{l}1.57(0.85) \\
1.23(0.99) \\
\text { NS }\end{array}$ & \\
\hline
\end{tabular}

Values are means (SD). In each patient values were determined in triplicate at rest and once at the end of pacing. FFA, free fatty acids.

myocardial alanine exchange at any time. Neither could any change in glucose exchange be demonstrated; values during pacing before and after propranolol were: aortocoronary sinus difference $0.13(0.14)$ vs $0.14(0.12) \mathrm{mmol} / \mathrm{l}$; fractional extraction $2.4(2.7)$ vs $2.4(2.4) \%$; net uptake $15.6(17.0)$ vs $17 \cdot 3(18 \cdot 4) \mu \mathrm{mol} / \mathrm{minute}$.

Changes in lactate, free fatty acid, and glutamate uptake in relation to changes in their arterial concentrations (Fig. 2)

The propranolol mediated changes in aortocoronary sinus differences of lactate correlated positively with the changes in its arterial concentration at rest but not during pacing. The same tendency was found after coronary sinus blood flow measurements were included; correlation coefficients between the changes in uptake and in load (arterial concentration multiplied by flow) of lactate were (eight patients) rest and pacing together, $\mathrm{r}=0.15$ (NS); rest, $\mathrm{r}=0.56$ (NS); pacing, $r=0.23$ (NS). The decrease in aortocoronary sinus free fatty acid difference correlated positively with the fall in its arterial concentration when data at rest and during pacing 


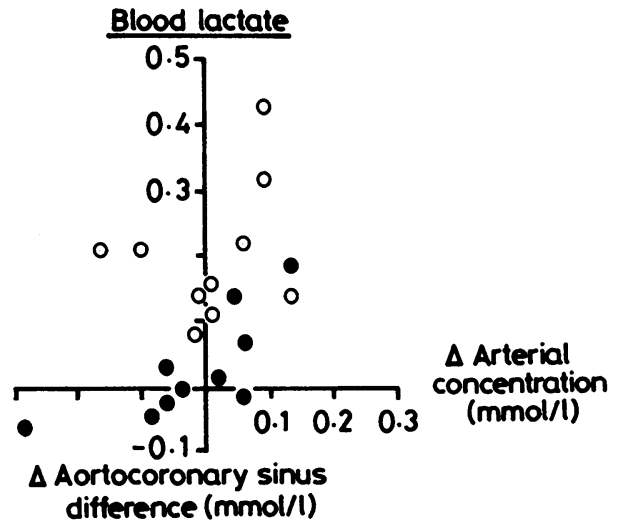

Plasma tree fatty acid

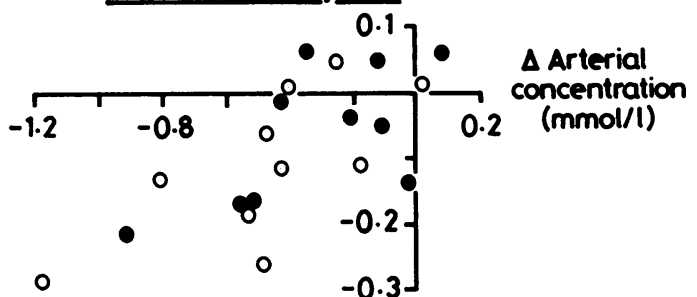

$\Delta$ Aortocoronary sinus difference (mmol/l)

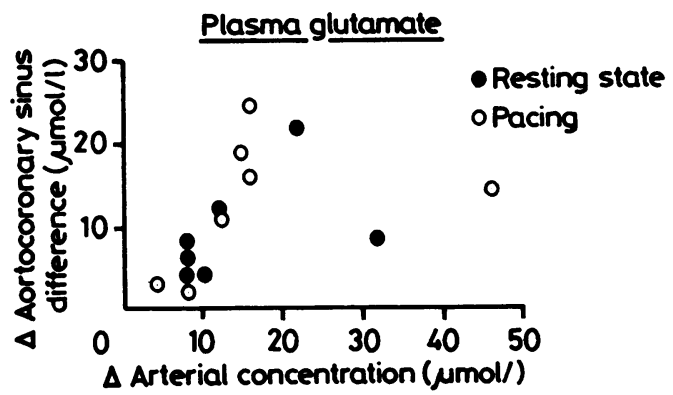

Fig. 2 Relations between the change in each patient after propranolol in aortocoronary sinus differences of blood lactate, plasma free fatty acids, and plasma glutamate, and the change in their arterial concentrations. Each $\Delta$ value is the value after propranolol minus that in control state. Blood lactate: all measurements $r=0.06, N S, n=20$; rest $r=0.71$, $p<0.05, n=10$; pacing $r=0.14, N S, n=10$. Plasma free fatty acids: all measurements $r=0.67, p<0.01, n=20$; rest $r=0.58$, NS $(p<0.1) ; n=10$; pacing $r=0.70, p<0.05$, $n=10$. Plasma glutamate: all measurements $r=0.39, N S$, $n=14$; rest $r=0.45, N S, n=7$; pacing $r=0.36, N S, n=7$.

were combined, during pacing, and insignificantly at rest. Correlation coefficients for the changes in free fatty acid uptake versus in load were: rest and pacing together, $r=0.62(p<0.01)$; rest; $r=0.24$ (NS); pacing, $r=0.54$ (NS). Figure 2 shows that there was a tendency towards a positive relation between the

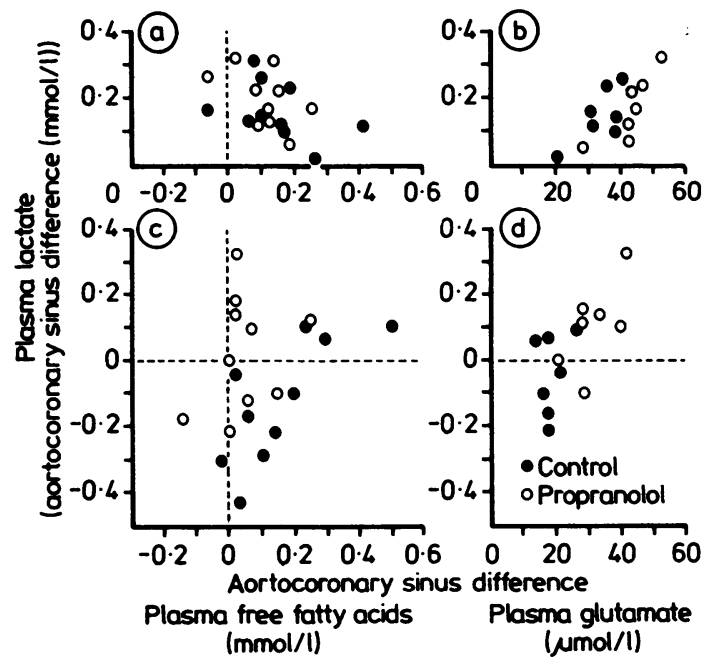

Fig. 3 Relations between aortocoronary sinus differences of blood lactate and corresponding values for plasma free fatty acids and plasma glutamate at rest $(a, b)$ and during pacing $(c, d)$ before and after administration of propranolol.

(a) All measurements $r=-0.45, p<0.05, n=20$; control state $r=-0.38, N S, n=10$; propranolol $r=-0.50, N S$, $n=10$.

(b) All measurements $r=0.63, p<0.05, n=14$; control state $r=0 \cdot 70, N S(p<0 \cdot 1), n=7$; propranolol $r=0.81$, $p<0.05, n=7$.

(c) All measurements $r=0.28, N S, n=20$; control state $r=0.73, p<0.05, n=10$; propranolol $r=0.23, N S, n=10$. (d) All measurements $r=0.69, p<0.01, n=14$; control state $r=0.35, N S, n=7$; propranolol $r=0.64, N S, n=7$.

increase in aortocoronary sinus glutamate difference and in its arterial concentration. For plasma glutamate changes in uptake versus in load the relation (seven patients) became significantly positive. These were the correlation coefficients: for rest and pacing together, $r=0.75(p<0.01)$; for rest, $r=0.90(p<0.01)$; and for pacing, $r=0.69(\mathrm{NS})$ $(\mathrm{p}<0.1)$.

Thus, during pacing the increase in extraction of lactate after propranolol did not correlate with changes in its supply to the heart. Both the reduction in free fatty acid and the increase in glutamate uptake after propranolol were positively related to the changes in their delivery from extracardial sources.

Interrelations between lactate and free fatty acid and glutamate exchanges (Fig. 3)

In the unstressed state before pacing values before and after propranolol for aortocoronary sinus lactate difference correlated inversely with free fatty acid differences and positively with glutamate differences (Fig. 3a and b). During pacing the lactate differences 
remained positively related to those of glutamate (Fig. 3d). Because of the limited number of patients studied, the same tendencies were found only when data before and after propranolol were considered separately. The relation between aortocoronary sinus lactate and glutamate differences at rest after propranolol, however, was statistically significant. The inverse relation between aortocoronary sinus differences between lactate and free fatty acids at rest was lost during pacing (Fig. 3c); but when values before propranolol were examined separately, the aortocoronary sinus lactate and free fatty acid differences correlated positively during pacing.

\section{Discussion}

We have examined the mechanisms that may underlie changes in myocardial metabolism after propranolol administration to patients with coronary artery disease.

As in previous studies of beta blockade during atrial pacing we found that myocardial oxygen uptake remained unchanged. ${ }^{3417}$ Determinants of myocardial oxygen consumption include heart rate, left ventricular contractility, and wall tension. ${ }^{18}$ Heart rate was controlled by pacing. The propranolol induced decrease in contractility and oxygen uptake was probably counterbalanced by left ventricular dilatation with a subsequent increase in wall tension. ${ }^{24}$ Coronary sinus blood flow and systemic haemodynamics were not influenced by propranolol. Beta adrenergic blockers may cause regional redistribution of myocardial blood flow in favour of ischaemic areas. ${ }^{19}$ This effect has been reported to be eliminated during pacing. ${ }^{20}$ Thus, the changes in substrate exchange across the heart found in the present study cannot be attributed to the haemodynamic effects of propranolol.

Despite unchanged heart work, there was evidence of an antianginal effect of propranolol. After the drug three patients did not develop angina, and pacing time until angina developed increased in four and was unchanged in three. Beta blockade has not consistently been reported to have a beneficial effect on clinical signs of pacing induced ischaemia. This is probably the result of methodological differences between studies. In particular, patients may have been insufficiently stressed. ${ }^{417}$ In our study all except one complained of angina before propranolol. In this patient, the effect of pacing at 140 beats/minute for 10 minutes may have been too low to induce ischaemia. In seven of the ten patients a release of lactate across the heart indicated the development of myocardial ischaemia during control pacing.

The energy requirements of the normal heart are met by oxidation of free fatty acids, glucose, and lactate. Lactate (by oxidation) and glucose (by glycolysis) are both converted to pyruvate. Oxidation of pyruvate is controlled at the site of pyruvate dehydrogenase. Free fatty acid catabolism inhibits pyruvate dehydrogenase by causing intracellular accumulation of acetyl-CoA and reduced nicotinamide adenine dinucleotide. ${ }^{21}$ Reduction of myocardial free fatty acid uptake and oxidation by nicotinic acid infusion augments glucose and lactate uptake of the normal human heart. ${ }^{7}$ The peripheral antilipolytic effect of propranolol ${ }^{6}$ leading to lowered arterial free fatty acid concentration with subsequent reduced free fatty acid oxidation and increased pyruvate dehydrogenase activity has been proposed as the mechanism underlying the augmented carbohydrate utilisation of the ischaemic heart after administration of the drug. ${ }^{4}$

Before pacing all patients had net lactate extraction, and none complained of chest pain. Propranolol did not change arterial lactate concentration. Yet, after the drug, changes in aortocoronary sinus lactate differences showed a significant positive relation to the changes in arterial lactate concentration at rest (Fig. 2), confirming that myocardial extraction of lactate is to some extent determined by supply. ${ }^{22}$ The inverse relation between aortocoronary sinus lactate and free fatty acid differences at rest (Fig. 3a) is consistent with the idea of competition between lactate and free fatty acid for entry into the citric acid cycle, though the increase in lactate extraction after propranolol did not reach statistical significance in our study.

The findings during pacing of increased myocardial lactate extraction and decreased net free fatty acid uptake after propranolol confirm the results of others. ${ }^{3-5}$ During pacing the changes in aortocoronary sinus lactate differences did not correlate with the changes in arterial lactate concentration (Fig. 2). After administration of atenolol, Thompson et al found that changes in myocardial lactate extraction and arterial free fatty acid concentration were inversely related both at rest and during atrial pacing. ${ }^{4}$ Only four of their eleven patients developed angina. They included all values obtained during gradual increases in heart rate to demonstrate the inverse relation between lactate extraction and free fatty acid supply during pacing. We were unable to demonstrate an inverse relation between aortocoronary sinus lactate and free fatty acid differences at end of pacing after patients had been stressed at a constant high rate (Fig. $3 c$ ). This, taken with the decrease in free fatty acid oxidation during ischaemia, ${ }^{9}$ raises the question of whether the reduced free fatty acid uptake at end of pacing 
after propranolol led to a further reduction in free fatty acid oxidation of a magnitude sufficient to explain the observed improvement in lactate extraction.

This suggestion is subject to limitations. Extraction of both lactate and free fatty acids decreases during ischaemia. Thus, at end of pacing an interrelation between lactate and free fatty acid aortocoronary sinus differences does not necessarily reflect substrate competition; it may merely reflect the relation between different markers of ischaemia, which may also explain the positive correlation between lactate and free fatty acid during control pacing before propranolol administration. Further, we measured net chemical free fatty acid uptake only. Experiments with labelled palmitate have demonstrated myocardial lipolysis, ${ }^{23}$ which is inhibited by propranolol. ${ }^{6}$ Although we did not measure changes in myocardial lipolysis, a reduction in myocardial free fatty acid oxidation after propranolol could explain the fall in myocardial citrate release during pacing and recovery. Oxidation of free fatty acids is the main determinant of myocardial citrate release. ${ }^{15}$ Citrate restriction of the glycolytic enzyme phosphofructokinase is an additional mechanism by which free fatty acids reduce utilisation of carbohydrate by the heart. ${ }^{24}$ Because propranolol reduced myocardial citrate release an increase in glucose uptake, as found in animal studies, is likely. ${ }^{25}$ The small absolute glucose aortocoronary sinus differences did not allow us to show this.

Reoxidation of glycolytically produced reduced nicotinamide adenine dinucleotide is among further mechanisms that may be important in the regulation of myocardial utilisation of lactate (and glucose). ${ }^{10}$ The inner mitochondrial membrane is impermeable to reduced nicotinamide adenine dinucleotide. Transfer of reducing equivalents, formed by reduction of cytosolic nicotinamide adenine dinucleotide, for oxidation in the mitochondrial electron transport chain occurs mainly indirectly via the malate-aspartate cycle when glucose is the substrate and probably exclusively by the mechanism when lactate is the substrate. ${ }^{1126}$ Flux through the shuttle is partly regulated by cytosolic glutamate concentration, ${ }^{26}$ and requires import of glutamate. ${ }^{12}$ An augmented myocardial glutamate supply may facilitate lactate extraction.

Our study demonstrates an increased arterial glutamate concentration after administration of propranolol. The underlying mechanisms are unknown. There was a consistent increase in aortocoronary sinus glutamate differences in the present study. Fractional extraction, however, did not change. The propranolol induced changes in aortocoronary sinus differences and in arterial concentrations tended to be positively related (Fig. 2). There was a positive statistically significant correlation between changes in glutamate uptake and load (arterial concentration multiplied by flow). Therefore the augmented extracardial supply of glutamate alone seems to be responsible for the increase in glutamate uptake across the heart. The findings that aortocoronary sinus lactate and glutamate differences correlated positively at rest and at end of pacing (Fig. $3 \mathrm{~b}$ and d) accord with the suggestion that an increased myocardial glutamate uptake is a possible mechanism for increasing lactate extraction in the unstressed state as well as at end of pacing. Although there is a physiological basis for these correlations, the proposed causality must be evaluated. Aortocoronary sinus lactate and glutamate differences decrease during ischaemia. ${ }^{16}$ Thus, as in the case of lactate versus free fatty acid differences, the relation between lactate and glutamate differences at end of pacing need not reflect an interaction between substrates; it may represent a relation between two markers of ischaemia.

Myocardial glutamate uptake is greater in patients with coronary artery disease than in normal controls. ${ }^{1316}$ Positron emission tomography has shown a high extraction of glutamate in ischaemic areas of the human heart despite reduced blood flow. ${ }^{27}$ Fractional extraction of glutamate is two to three times higher than that of lactate (Table). In one patient a global extraction of $70 \%$ suggests almost complete extraction of glutamate by the ischaemic zones. Thus, supply of glutamate may be a limiting factor for the maintenance of carbohydrate use.

There was no change in myocardial alanine release after propranolol; the slight fall in arterial alanine concentration may have been the result of an increase in the duration of the overnight fast during the second pacing study. ${ }^{28}$ Alanine release in part reflects alanine production from transamination of glutamate with pyruvate. ${ }^{29}$

The reduction in regional blood flow in ischaemic heart disease means that the direct effect of peripherally administered drugs upon the myocardium is likely to be moderate. In our study myocardial free fatty acid was reduced and glutamate uptake was increased after propranolol; findings which could be related to changes in the supply of each of the two substances, and thus be explained by extracardial actions of the drug - that is inhibition of peripheral lipolysis in the case of free fatty acid uptake and augmentation of the circulating concentration of glutamate. Both mechanisms seem to be important for improving myocardial lactate extraction in unstressed state. During pacing induced tachycardia the increased glutamate uptake may be of greater 
importance. Because myocardial oxygen uptake did not change, the results of our study support the idea of a metabolic contribution of propranolol in relieving angina that is additional to its haemodynamic effects.

This study was supported by grants from the Danish Heart Association.

\section{References}

1 Connolly ME, Kersting F, Dollery CT. The clinical pharmacology of the beta-adrenoceptor blocking drugs. Prog Cardiovasc Dis 1976; 19: 203-7.

2 Biamino G, Schröder R. What is the real pharmacological rationale for beta-receptor blocking agents? Eur Heart $\mathcal{F}$ 1983; 4 (suppl D): 137-41.

3 Armstrong PW, Choing MA, Parker JO. Effects of propranolol on the hemodynamic, coronary sinus blood flow and myocardial metabolic response to atrial pacing. Am f Cardiol 1977; 40: 83-9.

4 Thompson DS, Naqvi N, Juul SM, Coltart DJ, Jenkins BS, Webb-Peploe MM. Haemodynamic and metabolic effects of atenolol in patients with angina pectoris. $\mathrm{Br}$ Heart F 1980; 43: 668-79.

5 Jackson G, Atkinson L, Oram S. Improvement of myocardial metabolism in coronary arterial disease by betablockade. Br Heart $\mathcal{F}$ 1977; 39: 829-33.

6 Lech JJ, Jesmok GJ, Calvert DN. Effects of drugs and hormones on lipolysis in the heart. Fed Proc 1977; 36: 2000-8.

7 Lassers BW, Wahlqvist ML, Kaijser L, Carlson LA. Relationship in man between plasma free fatty acids and myocardial metabolism of carbohydrate substrates. Lancet 1971; ii: 448-50.

8 Nielsen TT, Henningsen P, Bagger JP, Thomsen PEB, Eyjolfsson K. Myocardial citrate metabolism in control subjects and patients with coronary artery disease. Scand F Clin Lab Invest 1980; 40: 575-80.

9 Vary TC, Reibel DK, Neely JR. Control of energy metabolism of heart muscle. Annu Rev Physiol 1981; 43: 419-30.

10 Kobayashi K, Neely JR. Control of maximum rates of glycolysis in rat cardiac muscle. Circ Res 1979; 44: 166-75.

11 Safer B. The metabolic significance of the malateaspartate cycle in heart. Circ Res 1975; 37: 527-33.

12 Digerness SB, Reddy WJ. The malate-aspartate shuttle in heart mitochondria. $\mathcal{F}$ Mol Cell Cardiol 1976; 8: $779-85$.

13 Thomassen A, Nielsen TT, Bagger JP, Thuesen L. Myocardial glutamate and alanine exchanges related to carbohydrate metabolism in patients with normal and stenotic coronary arteries. Clin Physiol 1984; 4: 425-34.

14 Ganz W, Tamura K, Marcus HS, Donoso R, Yoshida S, Swan HJC. Measurement of coronary sinus blood flow by continuous thermodilution in man. Circulation 1971; 44: 181-95.

15 Nielsen TT. Plasma citrate in relation to glucose and free fatty acid metabolism in man. Thesis. Dan Med Bull 1983; 30: 357-78.

16 Thomassen AR, Nielsen TT, Bagger JP, Henningsen P. Myocardial exchanges of glutamate, alanine and citrate in controls and patients with coronary artery disease. Clin Sci 1983; 64: 33-40.

17 Simonsen S, Ihlen H, Kjekhus JK. Haemodynamic and metabolic effects of timolol on ischaemic myocardium. Acta Med Scand 1983; 213: 393-8.

18 Braunwald E. Control of myocardial oxygen consumption: physiological and clinical considerations. $\mathrm{Am}$ f Cardiol 1971; 27: 416-32.

19 Saxena PR. Beta-adrenoceptor antagonists and blood flow to the jeopardized myocardium. Eur Heart $f$ 1983; 4 (suppl D): 101-8.

20 Warltier DC, Gross GJ, Hardman HF. Effect of Ndimethyl propranolol on regional myocardial blood flow and oxygen consumption in canine heart. $\mathcal{F}$ Pharmacol Exp Ther 1978; 204: 294-302.

21 Kerbye Al, Randle PJ, Cooper RM, Whitehouse S, Pask HT, Denton RM. Regulation of pyruvate dehydrogenase in rat heart. Biochem $\mathcal{F} 1976 ; 154: 327-48$.

22 Kaijser L, Lassers BW, Wahlqvist ML, Carlson LA. Myocardial lipid and carbohydrate metabolism in fasting men during prolonged exercise. $\mathcal{f}$ Appl Physiol 1972; 32: 847-58.

23 Most AS, Brachfeld N, Gorlin R, Wahren J. Free fatty acid metabolism of the human heart at rest. $\mathcal{F}$ Clin Invest 1969; 48: 1177-88.

24 Garland PB, Randle PJ, Newsholme EA. Citrate as an intermediary in the inhibition of phosphofructokinase in rat heart muscle by fatty acids, ketone bodies, pyruvate, diabetes and starvation. Nature 1963; 200: 169-70.

25 Opie LH. Propranolol and experimental myocardial infarction: substrate effects. Postgrad Med $\mathcal{F}$ 1976; 52 (suppl 4): 124-32.

26 Williamson JR, Safer B, Lanque K, Smith CM, Walajtys $\mathrm{E}$. Mitochondrial cytosolic interactions in cardiac tissue: role of the malate-aspartate cycle in the removal of glycolytic NADH from the cytosol. Symposia of the Society for Experimental Biology 1973; 27: 241-81.

27 Knapp WH, Helus F, Ostertag H, Tillmanns H, Kübler W. Uptake and turnover of $\mathrm{L}-(\mathrm{N}-13)$-glutamate in the normal human heart and in patients with coronary artery disease. Eur 9 Nucl Med 1982; 7: 211-5.

28 Elia M, Ilic V, Bacon S, Williamson DH, Smith R. Relationship between the basal blood alanine concentration and the removal of an alanine load in various clinical states in man. Clin Sci 1980; 58: 301-9.

29 Taegtmeyer H, Peterson MB, Ragavan VV, Ferguson AG, Lesch $M$. De novo alanine synthesis in isolated oxygen-deprived rabbit myocardium. $f$ Biol Chem 1977; 252: 5010-8. 